\title{
Zika Virus Speed and Direction: Reconstructing Zika Introduction in Brazil
}

\author{
Kate Zinszer ${ }^{2}$, Kathryn Morrison', John S. Brownstein ${ }^{2,4}$, Fatima Marinho ${ }^{5}$, \\ Santos F. Alexandre ${ }^{5}$ and Elaine O. Nsoesie ${ }^{\star 3}$
}

${ }^{1}$ McGill University, Montreal, QC, Canada; ' $B o s t o n$ Children's Hospital, Boston, MA, USA; ${ }^{3}$ University of Washington, Seattle, WA, USA; ${ }^{4}$ Harvard Medical School, Boston, MA, USA; ${ }^{5}$ Ministry of Health, Brasilia, Brazil

\section{Objective}

To estimate the velocity of Zika virus disease spread in Brazil using data on confirmed Zika virus disease cases at the municipal-level.

\section{Introduction}

Local transmission of Zika virus has been confirmed in 67 countries worldwide and in 46 countries or territories in the Americas (1,2). On February 1, 2016 the World Health Organization declared a Public Health Emergency of International Concern due to the increase in microcephaly cases and other neurological disorders reported in Brazil (2). Several countries issued travel warnings for pregnant women travelling to Zika-affected countries with Brazil, Colombia, Ecuador, and El Salvador advising against pregnancy (3-7). The risk of local transmission in unaffected regions is unknown but potentially significant where competent Zika vectors are present (8) and also given the additional complexities of sexual transmission and population mobility $(9,10)$. Despite the rapid spread of Zika virus across the Americas and global concerns regarding its effects on fetuses, little is known about the pattern of spread. Knowledge of the direction and the speed of movement of disease is invaluable for public health response planning, including the timing and placement of interventions.

\section{Methods}

Data for this analysis were obtained from the Brazil Ministry of Health and consisted of confirmed cases of Zika virus disease. The centroids of the municipalities were taken in meters from the shapefiles and used to perform a surface trend analysis. Surface trend is a spatial interpolation method used to estimate continuous surfaces from point data. The continuous surface of time to infection was estimated by regressing it against the $\mathrm{X}$ and $\mathrm{Y}$ coordinates. Time was in days and $\mathrm{X}$ and $\mathrm{Y}$ coordinates were meters. Parameters were estimated using least squares regression and velocity (in $\mathrm{km}$ per day) was obtained by inverting the final magnitude of the slope.

\section{Results}

Data provided from the Brazil Ministry of Health on May 31, 2016, indicated that Zika had been confirmed in 316 of the 5,564 municipalities in Brazil representing 26 states, with six additional municipalities identified from other reporting sources. Our models indicated a southward pattern of introduction of Zika starting from the northeast coast towards the southeastern coastal states of Rio de Janerio, Espírito Santo, and São Paulo. There was also a pattern of western movement towards Bolivia. Overall, the average speed of diffusion was $42.1 \mathrm{~km} /$ day across all models was $6.9 \mathrm{~km} /$ day to a maximum of $634.1 \mathrm{~km} /$ day. The municipalities in the Northeast and North regions had the slowest speeds whereas the municipalities in the Central-West and Southeast regions had the highest speeds. This is due to proximity of cases in time and space, with more cases having occurred closer in time and over larger areas in South, Southeast, and Central-West regions resulting in faster rates of introduction.

\section{Conclusions}

The average speed of spread was $42 \mathrm{~km}$ per day and it took approximately five to six months for Zika to spread from the northeastern coast to the southeastern coast and western border of Brazil. The rapid spread of Zika can help us understand its possible future directions and the pace at which it travels, which are key for targeted mosquito control interventions, public health messaging, and travel advisories. A multi-country analysis is needed to understand the continental spatial and temporal patterns of dispersion of Zika virus.

\section{Keywords}

Zika Virus; spatial; Brazil; surface trend analysis; velocity

\section{References}

1. Centers for Disease Control and Prevention. All countries \& territories with active Zika virus transmission. http://www.cdc.gov/zika/geo/ active-countries.html.

2. World Health Organization. Zika virus and complications. http://www. who.int/emergencies/zika-virus/en/.

3. Burke RM, Pandya P, Nastouli E, Gothard P. Zika virus infection during pregnancy: what, where, and why? Br J Gen Pract. 2016;66:122-3.

4. Government of Canada. Zika virus infection: global update. http://travel.gc.ca/travelling/health-safety/travel-health-notices/152? $\mathrm{ga}=1.38883366 .447391562 .1463768601$.

5. Goeijenbier M, Slobbe L, van der Eijk A, de Mendonça Melo M, Koopmans MP, Reusken CB. Zika virus and the current outbreak: an overview. Neth J Med. 2016;74:104-9

6. World Health Organization. Information for travellers visiting Zika affected countries. http://www.who.int/csr/disease/zika/informationfor-travelers/en/.

7. Alter C. Why Latin American women can't follow the Zika advice to avoid pregnancy [Internet]. New York, NY: Time Magazine, January 29, 2016. http://time.com/4197318/zika-virus-latin-america-avoidpregnancy/.

8. Messina JP, Kraemer MU, Brady OJ, et al. Mapping global environmental suitability for Zika virus. Elife. 2016;5:pii:e15272.

9. Basarab M, Bowman C, Aarons EJ, Cropley I. Zika virus. BMJ. 2016;352:11049.

10. Broutet N, Krauer F, Riesen M, Khalakdina A, Almiron M, Aldighieri $\mathrm{S}$, et al. Zika virus as a cause of neurologic disorders. N Engl J Med. 2016;374:1506-9.

\section{*Elaine O. Nsoesie}

E-mail: en22@uw.edu 